\title{
PENGEMBANGAN SISTEM ELEMEN PENGIKAT UNTUK MENINGKATKAN EFEKTIFITAS KEKANGAN KOLOM BANGUNAN TAHAN GEMPA
}

\author{
Kristianto, A. ${ }^{1}$, Imran, I. ${ }^{2}$, Suarjana, $M{ }^{2}{ }^{2}$ \\ ${ }^{1}$ Jurusan Teknik Sipil, Universitas Kristen Maranatha \\ Jalan Prof. drg. Soeria Sumantri, MPH, No. 65, Bandung, 40164 \\ e-mail: anang.kristianto@gmail.com \\ ${ }^{2}$ Jurusan Teknik Sipil, Institut Teknologi Bandung \\ Jalan Ganesa 10 , Bandung, 40132
}

\begin{abstract}
ABSTRAK
Indonesia merupakan daerah rawan gempa, belajar dari kerusakan bangunan yang ditimbulkan oleh kejadian beberapa gempa terakhir dibutuhkan suatu struktur yang benar-benar memenuhi persyaratan sebagai bangunan tahan gempa, baik pada saat perencanaan maupun implementasinya di lapangan. Kolom beton bertulang yang dibangun di daerah resiko gempa tinggi diharapkan mampu untuk bertahan dalam siklus deformasi inelastik dengan tetap memiliki kekuatan dan stabilitas struktur yang memadai. Hal ini dapat terjadi dengan memberikan tulangan pengekang yang tepat pada inti beton elemen struktur kolom. Salah satu persyaratan penting untuk konstruksi tahan gempa yang terkait dengan pendetailan tulangan adalah pemasangan tulangan pengekang dengan kait gempa $135^{\circ}$ pada elemen kolom beton bertulang. Pemasangan tulangan pengekang dengan kait $135^{\circ}$ tersebut tidaklah mudah. Untuk memudahkan pembuatan dan pemasangannya, banyak pelaksana konstruksi yang pada akhirnya menggunakan tulangan pengekang dengan kait $90^{\circ}$. Berdasarkan beberapa hasil penelitian dan beberapa catatan dari kejadian gempa di Indonesia akhir-akhir ini ,pemasangan tulangan pengekang dengan kait $90^{\circ}$ untuk kolom beton bertulang pada daerah rawan gempa dapat menghasilkan kinerja yang buruk dan berbahaya bagi sistem struktur bangunan secara keseluruhan. Tulisan ini mencoba untuk melakukan pengembangan suatu elemen tambahan yang diharapkan dapat meningkatkan efektivitas kekangan pada kolom dengan kait $90^{\circ}$. Elemen tambahan ini dapat ditambahkan dengan mudah dilapangan pada kolom dengan tulangan konvensional yang memiliki kait $90^{\circ}$. Penelitian dilakukan melalui serangkaian model finite elemen tulangan pengekang dengan menggunakan software ADINA. Efektivitas penambahan elemen pengikat untuk meningkatkan kinerja pada tulangan konvensional sengkang tertutup $90^{\circ}$ serta kait silang akan dianalisis. Penambahan elemen pengikat (pen-binder) cukup efektif untuk meningkatkan kinerja kolom beton bertulang dengan sengkang tertutup $90^{\circ}$.
\end{abstract}

Kata kunci: Kekangan, sengkang pengikat, elemen hingga,efektivitas

\begin{abstract}
Indonesia is an earthquake-prone region, learn from the damage of the last earthquake required a structure that truly meet the requirements of earthquake resistant buildings, both at the time of design and implementation in the field. Reinforced concrete columns built in seismically active regions are expected to undergo a large number of inelastic deformation cycles while maintaining overall strength and stability of structure. This can be ensured by proper confinement of the core concrete. One of the important requirements for earthquake resistant building associated with the installation of 135-degree hook-ties in reinforced concrete column elements. Installation of 135degree hook-ties is not easy, many construction executive used 90-degree hook-ties because of the ease of their placement compared with the 135-degree hook. Based on some research and some
\end{abstract}


records of earthquakes in Indonesia recently, installation of the 90-degree hook-ties for reinforced concrete columns in earthquake-prone areas can result in poor performance and dangerous for the building system structures. This study tried to develop an additional element that is expected to improve the effectiveness of concrete columns confined with 90-degree hook-ties. Additional element that can be attached on to the conventional 90-degree hook-ties or crossties at the sites. Research conducted through a series of modeling studies with a finite element method using ADINA software. The effectiveness of this additional element in improving the performance of conventional 90-degree hook-ties and crossties in columns was investigated. The pen-binder were found to be effective in improving the performance of concrete column confined with 90-degree hook-ties.

Key words : confinement, hook-ties, finite elements, effectiveness

\section{PENDAHULUAN}

Indonesia merupakan negara yang memiliki daerah dengan tingkat kerawanan gempa yang tinggi . Hal ini dapat dilihat dengan berbagai kejadian gempa dalam beberapa tahun terakhir yang melanda beberapa daerah di Indonesia (Imran et.al 2006,.Imran et.al.2007). Kondisi ini menyebabkan sistem struktur yang dibangun di Indonesia harus mengikuti kaidah bangunan tahan gempa sehingga pada saat terjadi gempa, struktur dapat bertahan dan melindungi penghuninya dari resiko bahaya gempa.

Namun dalam pelaksanaannya, untuk memenuhi kaidah tersebut tidaklah mudah. Salah satu masalah yang dapat teridentifikasi adalah yang terkait dengan pendetailan tulangan pada struktur bangunan beton bertulang tahan gempa khususnya tulangan pengekangan kolom. Pembuatan dan pemasangan tulangan pengekangan yang benar merupakan suatu keharusan karena hal ini memberikan peranan yang besar agar kolom dapat berperilaku daktail dan memenuhi konsep desain kapasitas. Peraturan perencanaan SNI 03-2847-02 mensyaratkan diberikannya tulangan pengekang dengan kait gempa $135^{0}$ pada elemen kolom yang dibangun pada daerah rawan gempa. Dalam prakteknya pembuatan dan pemasangan tulangan pengekang ini tidaklah mudah, apalagi untuk kolom-kolom berdimensi besar yang umum dipakai pada pada bangunan gedung tinggi seperti apartemen, jembatan dan jalan layang. Untuk memudahkan pembuatan dan pemasangannya, banyak pelaksana konstruksi yang pada akhirnya menggunakan tulangan pengekang yang dipasang dengan kait $90^{\circ}$. Menurut Imran et.al (2006) terkait dengan kerusakan struktur akibat gempa bumi di Indonesia memperlihatkan contohcontoh keruntuhan bangunan yang terjadi akibat pendetailan tulangan kolom yang tidak memenuhi persyaratan (Gambar 1), hasil penelitian juga membuktikan bahwa pemasangan tulangan pengekang dengan kait $90^{\circ}$ untuk kolom pada daerah rawan gempa dapat menghasilkan kinerja yang buruk dan berbahaya bagi sistem struktur secara keseluruhan. 
Oleh karena itu pemasangan tulangan pengekang dengan kait $90^{\circ}$ untuk elemen struktur kolom beton betulang pada dasarnya tidaklah direkomendasikan. Namun, walaupun demikian sistem ini ternyata banyak diaplikasikan di lapangan mengingat kemudahan dalam pemasangannya. Hal ini memotivasi penelitian untuk mengembangkan suatu perangkat tambahan yang dapat memperbaiki kinerja tulangan pengekang yang dipasang dengan kait gempa $90^{\circ}$ sedemikian sehingga sekalipun digunakan pengekang dengan kait gempa $90^{\circ}$, struktur kolom yang dihasilkan akan berperilaku daktail dan liat (tough), yaitu tidak gampang runtuh.
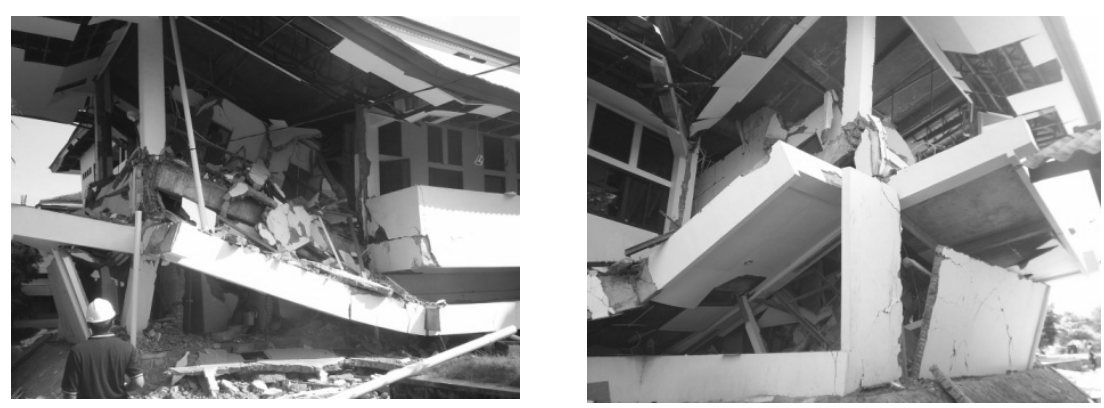

\section{Gambar 1. Contoh Keruntuhan Bangunan akibat Gempa Yogya yang Dipicu oleh Detailing Penulangan Kolom yang Tidak Tepat.(Imran I., 2006)}

\section{TINJAUAN LITERATUR}

Tulangan pengekang pada struktur kolom memiliki fungsi penting yaitu : mencegah menekuknya tulangan longitudinal, mencegah terjadinya keruntuhan geser dan mengekang inti beton sehingga elemen struktur kolom memiliki kemampuan untuk berperilaku daktail pada saat mengalami beban gempa ( Paultre P et.al., 2008)

Konsep pemasangan tulangan pengekang pada elemen struktur kolom beton bertulang dimaksudkan agar pada saat selimut kolom terkelupas dan akibatnya luas penampang kolom menjadi berkurang, maka tulangan pengekang diharapkan dapat mengekang inti beton sehingga kolom yang selimutnya telah terkelupas tersebut memiliki kekuatan paling tidak sama dengan kekuatan pada saat selimut kolom belum terkelupas. Akibat kekangan tulangan maka terdapat suatu area yang disebut luasan inti terkekang pada daerah sepanjang kolom. Luasan inti terkekang ini akan dipengaruhi salah satunya oleh konfigurasi tulangan pengekangnya ( Gambar 2 ) 


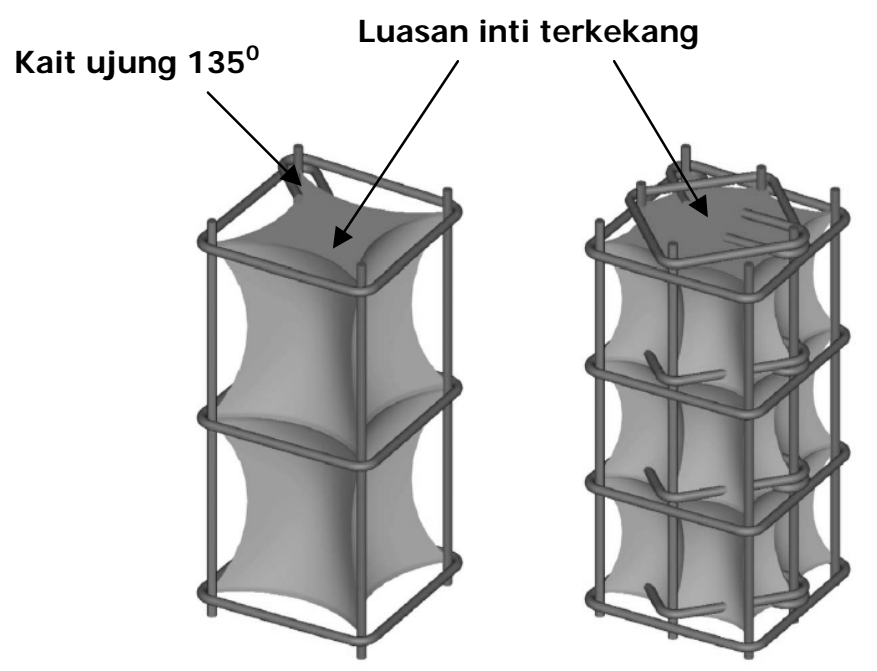

\section{Gambar 2. Luasan inti terkekang pada suatu elemen struktur kolom beton bertulang.(Paultre et.al.,2008)}

Agar dapat berfungsi dengan baik maka tulangan pengekang ini harus diikat dalam bentuk kait yang mengait pada tulangan longitudinal. Peraturan mensyaratkan untuk daerah rawan gempa tulangan pengekang harus dipasang dengan kait yang ujungnya ditekuk hingga $135^{\circ}$ seperti terlihat pada gambar diatas. Kait ujung yang ditekuk memiliki panjang sedemikian rupa sampai masuk pada daerah inti terkekang sehingga dapat memberikan tahanan yang baik dan kekangan berfungsi dengan efektif.

Tulangan pengekang dengan kait $90^{\circ}$ memiliki kemampuan yang lebih rendah dalam menahan inti beton, hal ini terjadi karena tidak ada gaya yang menahan kait tersebut untuk tetap pada posisinya pada saat beban gempa terjadi. Kondisi ini akan mengakibatkan kait membengkok keluar dan tidak efektif lagi mengekang inti beton ( Gambar 3 )

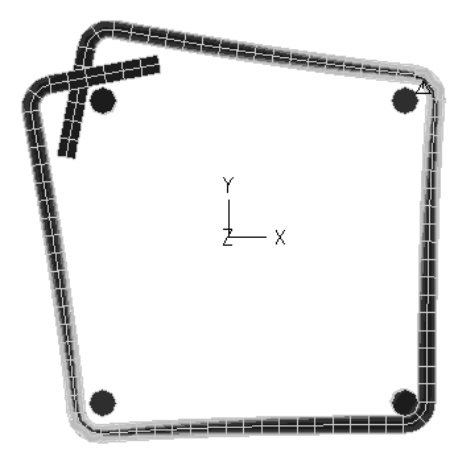

Gambar 3. Kegagalan Kait $90^{\circ}$ dalam menahan inti beton akibat beban aksial ( Output ADINA ) 


\section{Prinsip penting dalam berbagai penelitian beton terkekang.}

Beberapa prinsip penting yang didapat dalam penelitian beton terkekang :

\section{Pengaruh Beban Aksial}

Semakin tinggi beban aksial akan menurunkan tingkat daktilitas secara signifikan Sheikh dan Yeh 1990, Paultre dan Legeron, 2008 , level beban aksial biasanya diukur dari perbandingan P/fc'.Ag dan $\mathrm{P} / \mathrm{P}_{\mathrm{o}}$.( Gambar 4 )

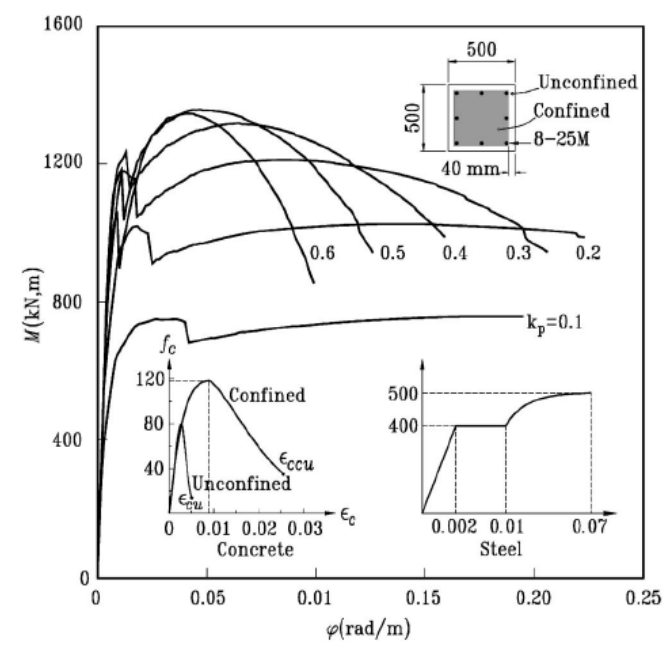

Gambar 4. Pengaruh Beban Aksial terhadap daktilitas (Paultreet.al., 2008)

\section{Konfigurasi Tulangan}

Efektifitas kekangan dari tulangan pengekang tergantung dari luas area efektif dari beton yang terkekang dan distribusi tegangan kekangannya, dimana hal ini dipengaruhi oleh distribusi tulangan longitudinal dan lateralnya (Sheikh et.al.,1990). Semakin banyak jumlah tulangan longitudinal yang dikekang oleh sengkang, area beton yang terkekang akan meningkat.

\section{Batasan Kondisi untuk Konfigurasi Tulangan.}

Sheikh dan Khoury ( 1997 ) menyarankan bahwa untuk desain beban gempa kolom harus didesain dan didetail dengan level daktilitas tinggi atau moderat. Berdasarkan beberapa eksperimen didapatkan bahwa konfigurasi kategori I tidak dapat digunakan untuk kolom dengan daktilitas tinggi. Pada kolom dengan konfigurasi kategori II, pengujian pada kolom F ( Sheikh \& Yeh., 1990; Sheikh \& Khoury., 1993 ; Sheikh et al., 1994 ) dengan beban aksial yang tinggi menunjukkan adanya kecenderungan terbukanya sengkang kait $90^{\circ}$ pada deformasi yang besar, dan mengakibatkan kolom kehilangan kekangan. Wehbe, Saiidi dan Sanders ( 1999 ), dalam pengujiannya terhadap kolom jembatan 
berbentuk segiempat yang didesain dalam level moderat menginformasikan bahwa pengekang dengan kait $90^{\circ}$ pada daerah sendi plastis sudah terbuka dan kondisi ini diikuti dengan menekuknya tulangan longitudinal akibat kehilangan kekuatan kekangan. Sementara pengekang dengan kait $135^{\circ}$ dalam kondisi mulai akan terbuka diikuti mulai menekuknya tulangan longitudinal pada akhir pengujian.

Lukkunaprasit dan Sittipunt 2003, menambahkan semacam hook-clips pada sambungan antara sengkang kait $90^{\circ}$ untuk menahan agar kait tidak terbuka. Hook-clips ini dilaporkan efektif mengekang kolom dengan sengkang kait $90^{\circ}$ yang didesain untuk level gempa moderat serta meningkatkan faktor daktilitas dan energi disipasinya.

Diperlukan penelitian lebih lanjut untuk level kegempaan yang lebih tinggi bila menggunakan tulangan pengekang dengan kait $90^{\circ}$ yang diberikan elemen pengikat, mengingat tulangan pengekang yang diberi kait dengan sudut ini lebih praktis dalam pelaksanannya secara khusus sangat berguna bila diimplementasikan pada kolom jembatan atau bangunan tinggi yang rata-rata berdimensi besar.

\section{Tinjauan Mengenai Pengekangan Kolom Beton Bertulang pada Peraturan .}

Bila suatu penampang beton bertulang mendekati kekuatan penuhnya sebelum baja leleh, maka penampang tersebut juga mengalami peningkatan deformasi arah aksial maupun lateral sebelum penampang mengalami kehancuran. Untuk memperlambat kehancuran penampang beton maka digunakan tulangan pengekang. Tulangan pengekang dipasang dengan maksud agar pada saat terjadi spalling pada pelindung beton, kolom tidak akan kehilangan kekuatan aksialnya.

Kekuatan kolom sebelum selimut terkelupas :

$$
P_{0}=0.85 \cdot f c^{t} \cdot\left(A_{g}-A_{g t}\right)+A_{g t} \cdot f_{y}
$$

Kekuatan kolom setelah selimut terkelupas :

$$
P_{1}=0.85 . f_{1 *}\left(A_{e}-A_{s t}\right)+A_{s t} f_{y}
$$

Dimana $\mathrm{A}_{\mathrm{g}}=$ luas penampang total, $\mathrm{A}_{\mathrm{st}}=$ luas total tulangan longitudial, $\mathrm{A}_{\mathrm{c}}=$ luas penampang setelah selimut terkelupas, $\mathrm{f}_{1}=$ kuat tekan setelah kekangan bekerja, $\mathrm{f}_{\mathrm{y}}=$ mutu tulangan longitudinal. Sesuai dengan konsep bahwa diharapkan kekuatan kolom minimum sama sebelum dan sesudah selimut lepas maka $\mathrm{P}_{0}=\mathrm{P}_{1}$, Bila luas tulangan baja Ast diabaikan karena terlalu kecil dibandingkan dengan luas penampang kolom maka :

$$
f_{1}=\frac{A_{\Omega} f_{\varepsilon}^{t}}{A_{\varepsilon}}
$$


Berdasarkan penelitian ( Richart et.al., 1928 ) dengan adanya kekangan maka kekuatan tekan inti beton pada kolom akan menjadi sebesar :

$$
f_{1}=f c^{l}+4.1 . f_{2}
$$

Rasio volumetrik tulangan kekang didefinisikan sebagai perbandingan volume tulangan kekang terhadap volume inti beton, untuk tulangan spiral maka :

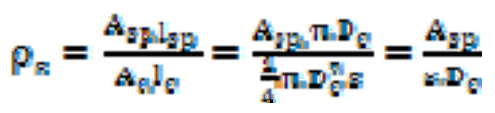

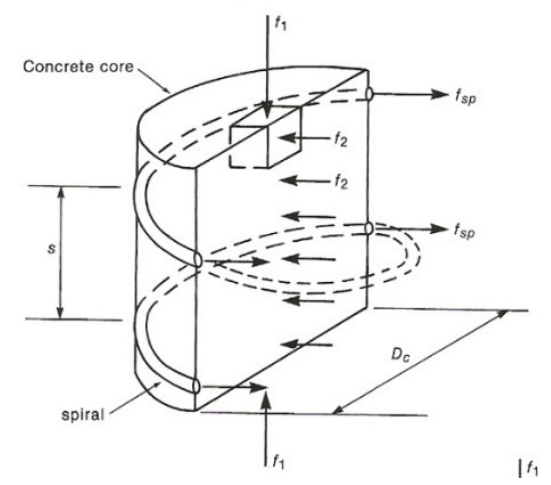

\section{Gambar 5. Gaya Pada Beton Terkekang (MacGregor,2005)}

Tegangan kekangan $\left(\mathrm{f}_{2}\right.$ ) dihitung dengan asumsi bahwa tulangan kekang telah mencapai tegangan lelehnya (fy) pada saat kolom mengalami kegagalan. Sesuai dengan keseimbangan freebody (Gambar 5) untuk mendapatkan besarnya tegangan kekang lateral pada inti beton yang dihasilkan oleh pengekangan tulangan, maka jumlah aljabar gayagaya tersebut menjadi :

$$
\begin{aligned}
& \mathrm{f}_{2} \cdot \mathrm{s}_{\mathrm{n}} \mathrm{h}_{\mathrm{u}}=2 . \mathrm{A}_{\mathrm{u \mu}} \mathrm{f}_{\mathrm{yh}} \\
& f_{2}=\frac{2 A_{3 N} f_{y}}{\varepsilon_{v} s}=\frac{f_{s p} \rho_{s}}{2}
\end{aligned}
$$

Sehingga dengan mensubstitusi persamaan diatas maka SNI 03-2847-2002 (pasal 23.4) menetapkan rasio volumetrik minimum tulangan transversal untuk kolom lingkaran sebesar :

$$
\begin{aligned}
& \rho_{\mathrm{s}}=0.45\left(\frac{A_{\Omega}}{A_{v}}-1\right) \frac{f_{h}^{b}}{f_{\mathrm{gh}}} \quad \text { atau } \\
& \rho_{s}=0.12 . \frac{f_{s}^{r}}{f_{\text {fin }}}
\end{aligned}
$$

Untuk kekangan pada kolom persegi maka sesuai dengan konsep diatas maka persamaan menjadi :

$$
A_{s h}=0.3 . s_{n} k_{\sigma} \cdot\left[\frac{A_{g}}{A_{\sigma}}-1\right] \cdot \frac{f \sigma t}{f_{\mathrm{ght}}}
$$




$$
A_{\mathrm{v} / \mathrm{t}}=0.09 .5 \cdot h_{\mathrm{v}} \cdot \frac{f_{\mathrm{v}}}{f_{\mathrm{v} z}}
$$

Selain persyaratan rasio volumetrik tulangan, peraturan juga memberikan persyaratan kekangan untuk desain elemen kolom pada daerah dengan tingkat kerawanan bahaya gempa yang tinggi. SNI 03-2847-2002 mendefinisikan “ sengkang kait gempa” ( seismic hook , Gambar 6) sebagai kait pada sengkang terbuka ( Detail-C) , tertutup ( Detail-A) atau pada pengikat silang ( Detail-B) yang ujungnya ditekuk dengan sudut tidak kurang dari $135^{\circ}$.

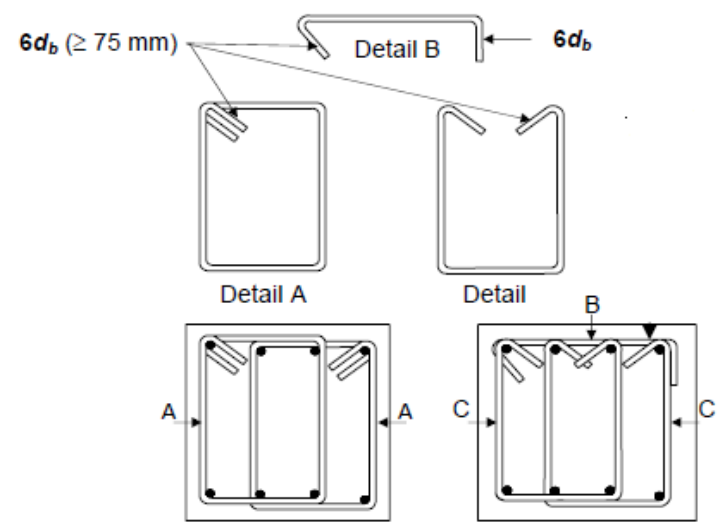

Gambar 6. Detail Sengkang Kait Gempa ( SNI 03-2847-2002)

Detailing diperlukan pada daerah-daerah yang diharapkan terbentuk sendi plastis untuk mendisipasi energi gempa yang masuk dalam struktur.( Gambar 7)

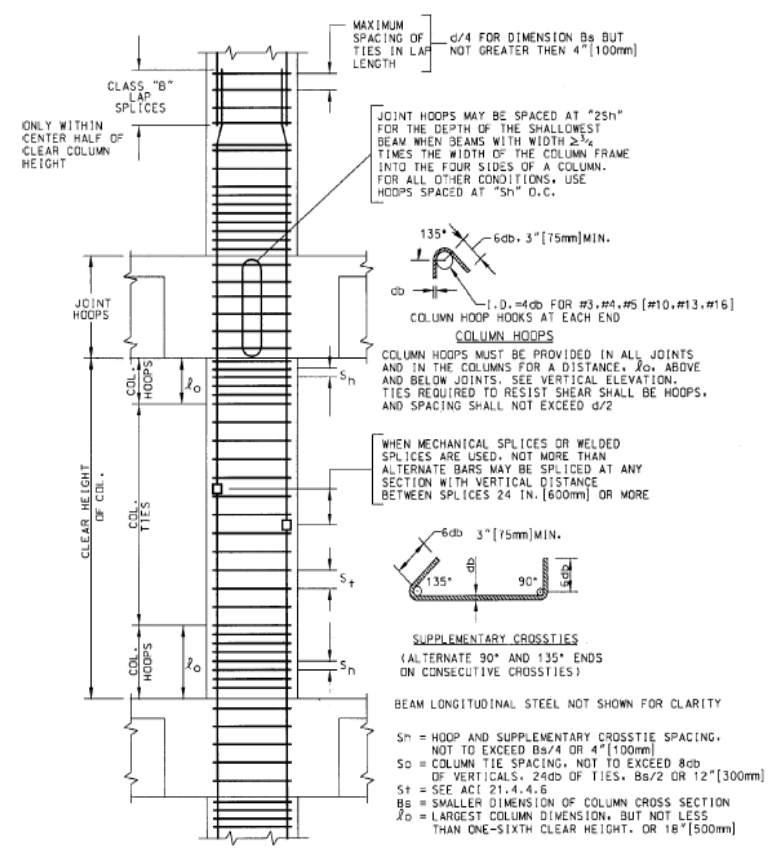

Gambar 7. Detailing kekangan pada kolom untuk daerah dengan tingkat kerawanan gempa tinggi (ACI 318M-05) 


\section{STUDI PEMODELAN TULANGAN PENGEKANG PADA KOLOM}

Studi pemodelan tulangan pengekang untuk kolom persegi dilakukan berdasarkan model kekangan yang dikembangkan oleh Saatcioglu M dan Razvi S.R (2002). Seperti terlihat pada gambar 8 .
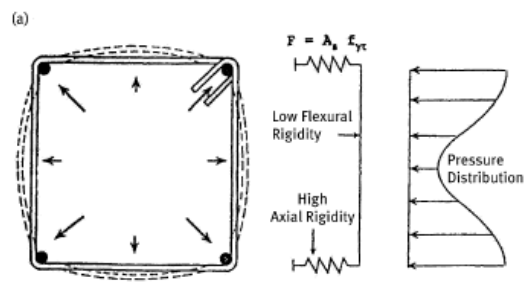

(c)

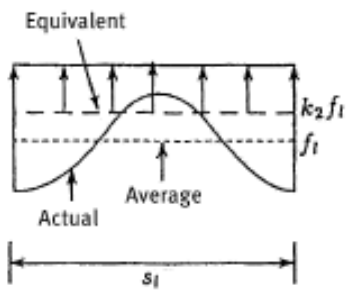

(b)

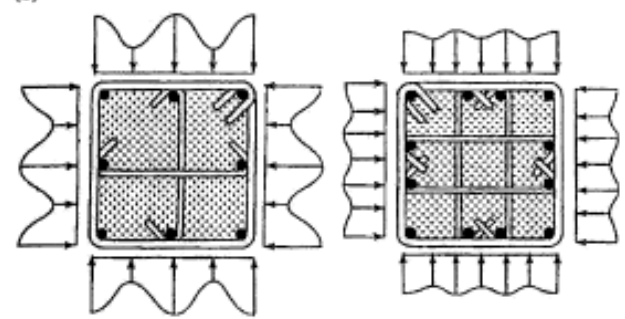

(d)

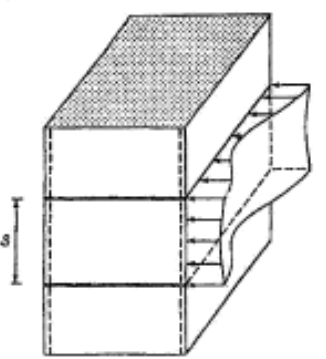

Gambar 8. Tegangan Kekangan pada kolom persegi : adan b. kolom persegi dengan berbagai konfigurasi, c. Tegangan aktual, rata-rata dan ekivalen, d.distribusi tegangan sepanjang tinggi kolom.( Saatcioglu M. and Razvi

$$
\text { S.R.,2002) }
$$

Persamaan berikut mendefinisikan peningkatan kekuatan pada beton terkekang secara analitis sesuai dengan model diatas

$$
\begin{aligned}
& f_{m}^{t}=f_{m}^{t}+k_{1} \cdot k_{2=} f_{k} \\
& f_{i}=\frac{\sum A_{s} f_{v s}}{s \cdot b_{v}} \\
& k_{1}=6.7\left(k_{2} f_{i}\right)^{-0.17} \\
& k_{2}=0.26 \cdot \sqrt{\frac{v_{g}}{g} \cdot \frac{b_{g}}{s_{i}} \cdot \frac{1}{f l}}
\end{aligned}
$$

Dimana :

$f_{c \varepsilon}^{\prime}=$ Kuat tekan beton terkekang ( Mpa)

$f_{\circ o}^{t}=$ Kuat tekan beton $=0.85 \mathrm{fc}^{\prime}$

$f_{l}=$ Tegangan yang bekerja pada pengekang lateral ( Mpa )

$\mathrm{k}_{1}=$ koefisien yang menyatakan hubungan antara tegangan pengekang dan peningkatan kekuatan.

$\mathrm{k}_{2}=$ koefisien yang menyatakan efisiensi tulangan pengekang. 
Untuk menganalisis perilaku pengekangan dibuat 5 macam model kolom persegi dengan karakteristik sebagai berikut. Tabel 1. Model kolom dengan dimensi 200mmx200 $\mathrm{mm}$, mutu beton digunakan $\mathrm{fc}^{\prime}=25 \mathrm{Mpa}$, tulangan longitudinal dan pengekang digaunakan diameter 13mm dan 10mm dengan mutu tulangan 400MPa

Sesuai dengan persamaan (12) sampai (15) berdasarkan data pada model kolom diatas didapatkan distribusi tegangan yang bekerja pada kekangan $\mathrm{f}_{1}=1.545 \mathrm{MPa}$, distribusi ekivalen $\mathrm{f}_{\text {ekivalen }}=\mathrm{k}_{2} \cdot \mathrm{f}_{\mathrm{l}}=(0.21) \cdot(1.545 \mathrm{MPa})=0.324 \mathrm{MPa}$. Selanjutnya distribusi tegangan dibuat menjadi beban merata yang bekerja pada tulangan pengekang sesuai dengan gambar pada Tabel 1.

Tabel 1. Model Benda Uji

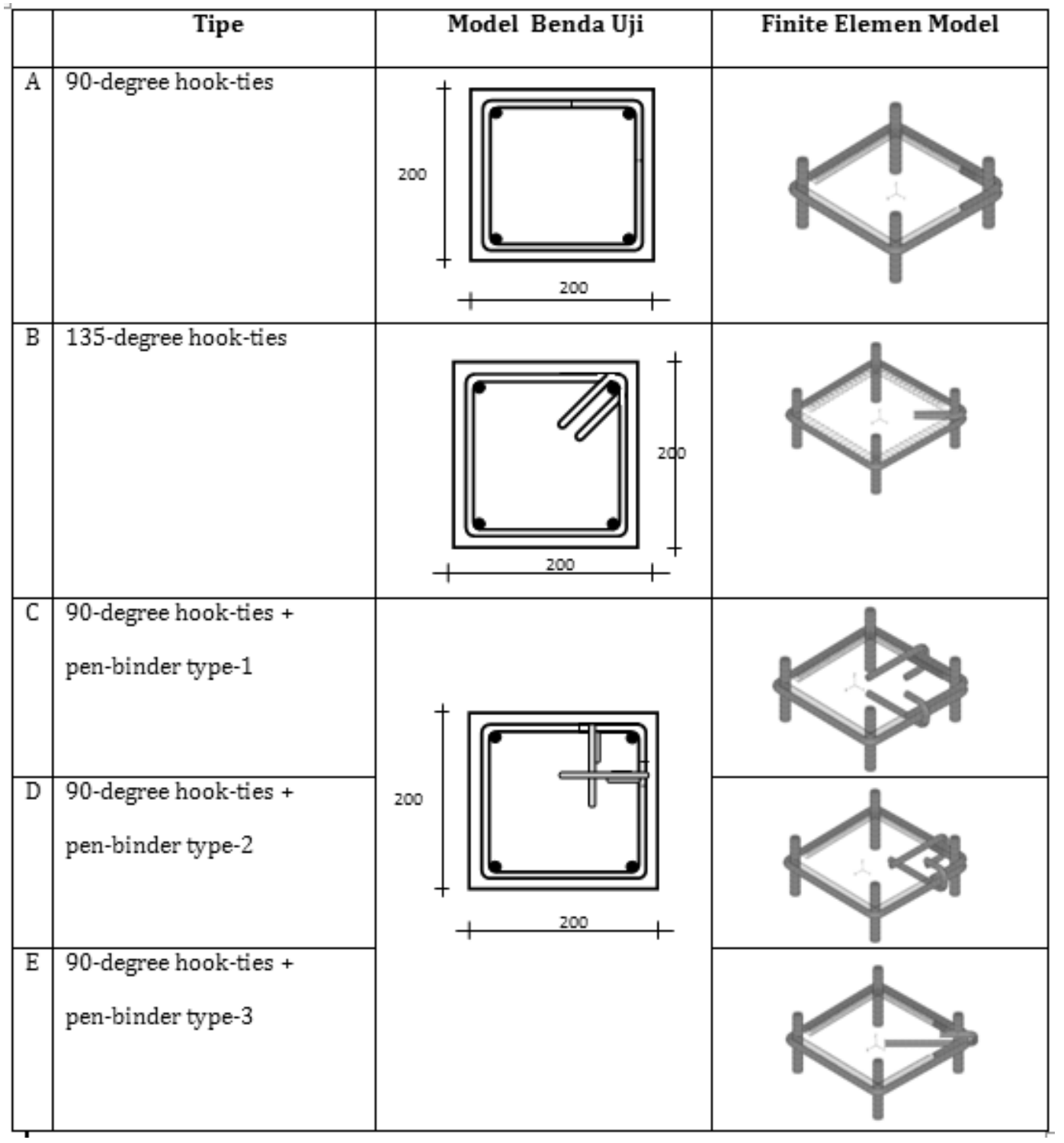


Pemodelan dan analisis menggunakan software ADINA, salah satu keistimewaan software ini adalah kemampuan untuk menganalisis tegangan kontak antara beberapa elemen struktur dengan karakteristik material yang berbeda. Software ini juga memiliki kemampuan untuk membuat berbagai bentuk model 3 dimensi dengan baik dan cepat serta menghasilkan output yang cukup detail.

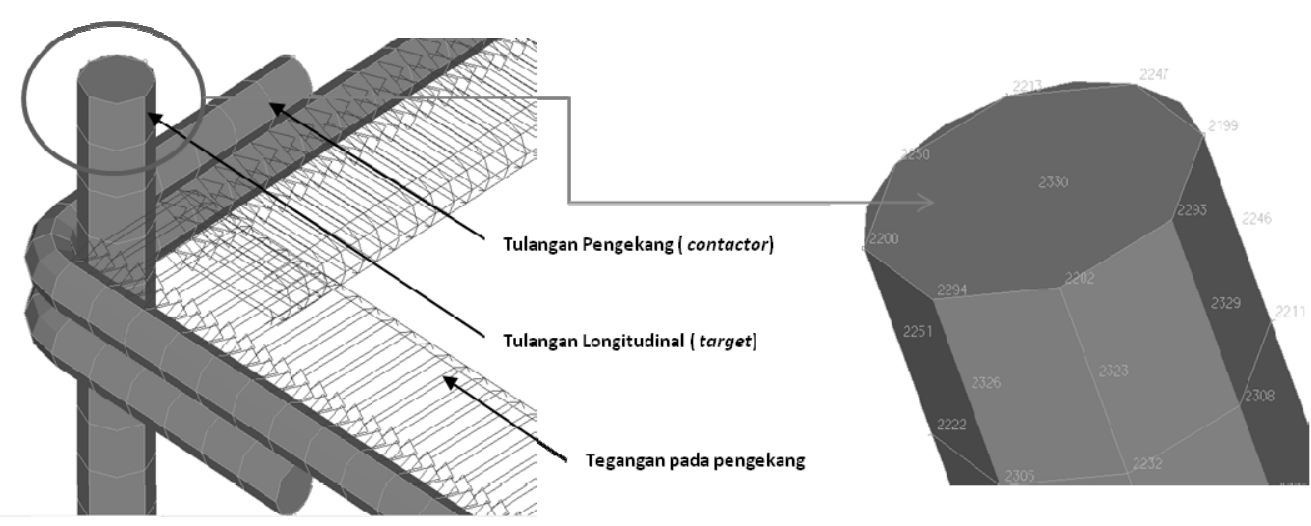

Gambar 9. Detail model ( Input ADINA )

Model A merupakan kolom dengan kait gempa $90^{\circ}$, model B merupakan kolom dengan kait gempa $135^{\circ}$, sedangkan model C,D dan E merupakan kolom dengan kait gempa $90^{\circ}$ yang diberikan elemen pengikat (pen-binder ) pada bagian tengah, seperempat jarak tulangan longitudinal, dan pada sudut yang terdapat kait $90^{\circ}$. Pemodelan dilakukan dengan menggunakan 3D solid elemen dengan 27 node untuk setiap mesh elemen (Gambar 9 dan 10) dan ukuran mesh yang optimum dibuat untuk mendapatkan data tegangan yang akurat.
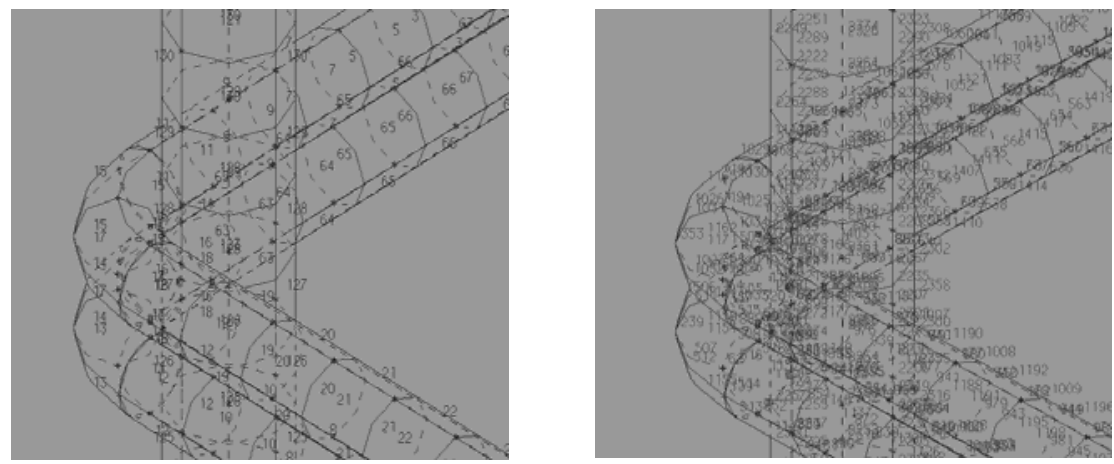

\section{Gambar 10. Penomoran elemen dan nodal}

Tulangan longitudinal pada kedua ujungnya dimodelkan sebagai sendi yang tidak dapat bergerak pada arah horisontal, pada ujung bawah dimodelkan tidak dapat bergerak 
kebawah. Tulangan pengekang dimodelkan sebagai rol yang dapat bergerak pada arah horisontal tetapi tetap pada arah vertikal untuk mendapatkan perilaku deformasi yang terjadi. Pada pertemuan tulangan longitudinal dan tulangan pengekang serta pertemuan tulangan elemen pengikat dan tulangan pengekang dilakukan analisis kontak untuk mendapatkan perilaku pertemuan antara kedua elemen tersebut.

Hasil analisis komputer untuk ketiga pemodelan diatas menghasilkan perilaku deformasi tulangan pengekang seperti terlihat pada Tabel 2.

Tabel 2. Deformasi model benda uji.

\begin{tabular}{|l|l|l|}
\hline & & Finite Elemen Model \\
\hline A & 90 -degree hook-ties & Deformation \\
\hline B & $\begin{array}{l}\text { 135-degree hook-ties } \\
\text { pen-binder type-1 }\end{array}$ & $\begin{array}{l}\text { go-degree hook-ties } \\
\text { pen-binder type-2 }\end{array}$ \\
\hline $\begin{array}{l}\text { 90-degre hook-ties } \\
\text { pen-binder type-3 }\end{array}$
\end{tabular}


Pada tabel 2 terlihat bahwa tulangan pengekang dengan kait 90 tanpa penambahan elemen pengikat mengalami deformasi yang cukup besar sehingga tidak efektif mengekang inti beton pada kolom, sementara tulangan pengekang dengan kait 135 derajat memberikan kekangan yang baik.

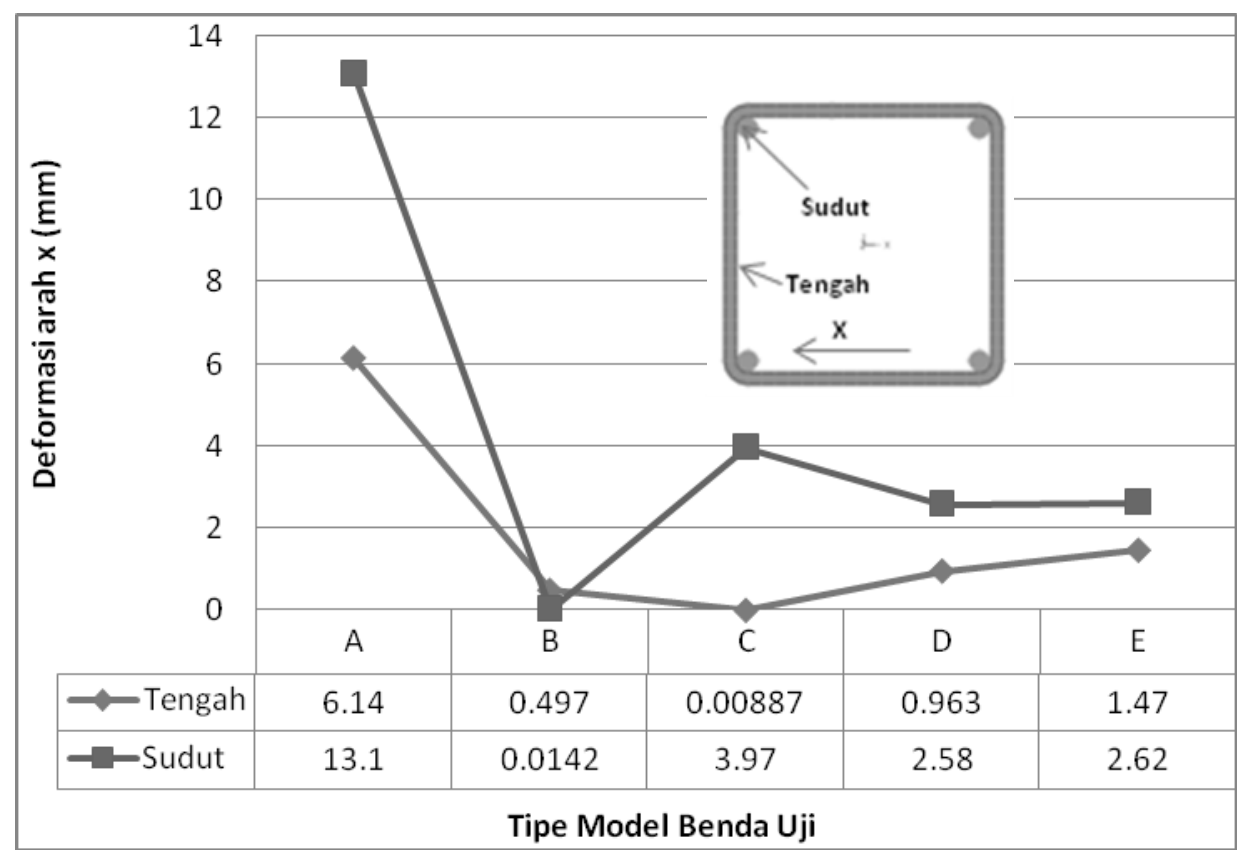

Gambar 11. Grafik deformasi tulangan pengekang

Gambar 11 memperlihatkan deformasi pada bagian sudut yang terdapat kait 90 dan 135 serta pada bagian tengah diantara dua tulangan longitudinal. Grafik diatas menunjukkan deformasi yang cukup besar terjadi pada model A, sementara model dengan tambahan elemen pengikat (C,D dan E ) memperlihatkan deformasi yang relatif lebih kecil yaitu sebesar berturut-turut 30.3\%, 19.7\% dan 20\% dari deformasi model A meskipun belum dapat menyamai model B.

Hasil analisis diatas menunjukkan suatu perbedaan efektivitas pengekangan yang cukup besar antara tulangan pengekang dengan kait $90^{\circ}$ dan $135^{\circ}$. Perilaku ini memperkuat pembuktian bahwa kekangan dengan kait $90^{\circ}$ tidak cukup efektif untuk memberikan kekangan pada inti beton pada saat kolom mengalami beban gempa. Pemberian elemen pengikat tambahan memberikan hasil yang cukup signifikan dalam memberikan kekangan pada inti beton, hal ini dapat dilihat dari perilaku deformasi ujung kekangan pada model C,D dan E yang relatif jauh lebih kecil daripada model A. Untuk melihat efektivitas kekangan dengan adanya tambahan elemen pengikat perlu dilakukan analisis yang lebih mendalam, komprehensif serta pengujian laboratorium menggunakan benda uji kolom dengan berbagai parameter yang divariasikan. 


\section{KESIMPULAN}

Beberapa hal penting yang dapat disimpulkan dari penelitian pada kasus kolom diatas adalah :

1. Penggunaan tulangan sengkang dengan kait $90^{\circ}$ tidak memberikan kekangan yang cukup efektif pada kolom yang dibangun pada daerah rawan gempa

2. Agar dapat berperilaku daktail pada saat mengalami beban gempa diperlukan tulangan pengekang dengan kait $135^{\circ}$ karena terbukti efektif mengekang beton pada struktur kolom.

3. Penambahan elemen pengikat pada kekangan dengan kait $90^{\circ}$ sedemikian rupa yang tertanam pada daerah inti beton memberikan kekangan yang relatif lebih baik serta cukup signifikan meskipun belum dapat menyamai kolom dengan kait $135^{0}$.

\section{SARAN}

Penelitian mengenai efektivitas pengekangan dengan penambahan elemen pengikat ini masih memerlukan studi lanjut dalam analisis numerik elemen hingga maupun pengujian di laboratorium.

Perlunya alternatif bentuk elemen pengikat lainnya sehingga didapatkan bentuk elemen pengikat yang sederhana dan mudah pelaksanaannya.

\section{DAFTAR PUSTAKA}

1. Chen W.F , Lan Y.M., 2006, Finite Elemen Studi of Confined Concrete, ACISpecial Publication ( SP-238-14).

2. Djauhari Z. , I. Imran., 2008, Study of Confinement Models for High Strength Concrete Confined by High Strength Steel, Proceeding International Conference on Earthquake Engineering and Disaster Mitigation ( ICEEDM '08 ), Jakarta.

3. Hoedajanto, D., Imran I., 2002, The Practice of Concrete Engineering in Indonesia, Proceedings of Asian Concrete Forum Symposium, Seoul, Korea, pp.107-113

4. Imran, I., Suarjana, M., Hoedajanto, D., Soemardi, B., Abduh, M., 2006, Beberapa Pelajaran dari Gempa Yogyakarta; Tinjauan Kinerja Struktur Bangunan Gedung, Jurnal HAKI, Vol. 7, No. 1, hal. 1-13 (ISSN No. 0216/5457)

5. Imran, I., 2007, The 6 March 2007 West Sumatera Earthquake-Lesson Learned and Recommendations, Prosiding The International Symposium on Disaster in Indonesia (ISDI): Problem and Solution, 26-28 Juli, Padang.

6. Imran, I., Hoedajanto, D., Suharwanto, 2005, Beberapa Pelajaran dari Gempa Aceh; Tinjauan Kinerj Dua Bangunan Perkantoran di Banda Aceh, Seminar Gempa HAKI 2005, Jakarta, 25 Mei, (ISBN 979-98441-2-6) 
7. Lukkunaprasit, P ; Sittipunt C., 2003, Ductility Enhancement of Mederatly Confined Concrete Tied Column with Hook-Clips , ACI Structural Journal, V. 100, No. 4, July.-August. 2003, pp. 422-429.

8. Richart, F. E., Brandtzaeg, A., and Brown, R. L.,1928. A study of the failure of concrete under combined compressive stresses. Engrg. Experiment Station Bull. No. 185, University of Illinois, Urbana, Ill.

9. Saatcioglu M. and Razvi S.R.,2002, Displacement-Based Design of Reinforced Concrete Columns for Confinement,ACI Structural Journal V.99. No1, JanuaryFebruari,2002,pp. 3-11.

10. Paultre P.; Legeron F., 2008, Confinement Reinforcement Design for Reinforced Concrete Columns, ASCE Journal of Structural Engineering, Vol 134. No5 May 2008.

11. Purwono, R., Tavio, Imran, I., Raka, I.G.P, 2006, Indonesian Concrete Code for Buildings ( SNI 03-2847-2002 ) with Commentary, ITS Press, Surabaya, Indonesia.

12. Sheikh, S. A., and Yeh, C., 1990, Tied Concrete Columns under Axial Load and Flexure, Journal of Structural Engineering, ASCE, V. 116, No. 10, Oct. 1990, pp. 2780-2800.

13. Wehbe, N. I.; Saiidi M. S.; and Sanders, D. H., 1999, Seismic Performance of Rectangular Bridge Columns with Moderate Confinement, ACI Structural Journal, V. 96, No. 2, Mar.-Apr. 1999, pp. 248-258.

14. Widodo, 2007, Kerusakan Bangunan Pada Gempa Jogyakarta 27 Mei 2006 Akibat Kebelumjelasan Code, Sosialisasi atau Pelaksanaan ?, Prosiding Seminar HAKI 2007. Jakarta. 